\title{
Implementing a Smoke-free Medical Campus: Impact on Inpatient and Employee Outcomes
}

Anne M. Gadomski, MD, MPH ${ }^{1}$ Marti Stayton ${ }^{2}$

Nicole Krupa, ms $^{3}$

Paul Jenkins, $\mathrm{PhD}^{3}$

\author{
${ }^{1}$ Research Institute, Bassett Healthcare, Cooperstown, New York. \\ ${ }^{2}$ Employee Assistance, Bassett Healthcare, Cooperstown, New York. \\ ${ }^{3}$ Computing Center, Bassett Research Institute, Cooperstown, New York.
}

\begin{abstract}
The New York State Bureau of Tobacco Control and Prevention funded this study as a Promising Interventions grant. This study was presented at the National Conference on Tobacco or Health, Minneapolis, MN, October 24, 2007.
\end{abstract}

Disclosure: Nothing to report.

BACKGROUND: Hospitals fear that transitioning to a smoke-free medical campus will decrease patient volume, particularly for patients who smoke. When our hospital campus, a 180-bed acute care facility located in a small town, implemented the smoke-free medical campus on July 1, 2006, we prospectively monitored inpatient and employee outcomes.

METHODS: Inpatient volume, percentage of inpatients who currently smoke, nicotine replacement therapy (NRT) orders (obtained from electronic medical records), the number of inpatients who signed out against medical advice (obtained from incident reports), and employee tobacco-use rates from annual occupational health assessments were compared pre-ban and post-ban.

RESULTS: The monthly average for the percentage of inpatients who currently smoke has been steady, at $20 \%$ to $22 \%$ postban. NRT orders tripled after the ban. There was no significant change in the rate of inpatients who signed out against medical advice pre-ban and post-ban. During the year preceding the ban, 150 employees participated in a cessation program offered by Employee Health. The pre-ban employee self-reported smoking rate for the same 4-month period (March-June) was $14.3 \%$ in $2005,14.8 \%$ in 2006, and $9 \%$ in $2007(P<0.0002)$.

CONCLUSIONS: Implementing a smoke-free medical campus did not adversely affect inpatient volume (even among smokers), significantly increased inpatient NRT use, and decreased hospital employee smoking rates. Journal of Hospital Medicine 2010;5:51-54. @ 2010 Society of Hospital Medicine.

KEYWORDS: employee smoking rates, inpatient volume, nicotine replacement therapy, smoke-free medical campus.

Even though imposition of smoke-free policies and workplaces comprise one of the most effective antismoking strategies, ${ }^{1}$ hospital administrators hesitate to implement a smoke-free medical campus policy. ${ }^{2}$ They fear losing patients who smoke because these patients will opt for other facilities that permit smoking.

Apart from studies evaluating Joint Commission on Accreditation of Healthcare Organizations (JCAHO)-required indoor smoking bans in hospitals in 1992, ${ }^{3,4}$ there are few published studies or formal evaluations of the impact of medical campuses going smoke-free. One study of the implementation of a smoke-free medical campus policy at a university hospital in Little Rock, AR, showed that the policy had no impact on employee retention, bed occupancy, or mean daily census; however, inpatient smoking status was not ascertained. ${ }^{5}$ Most (83\%) employees were supportive of the policy. More importantly, employees at 2 university medical centers reported reduced cigarette consumption and increased attempts to quit after implementation of a smoke-free medical campus policy. ${ }^{6,7}$

Our hospital is 180-bed, acute care inpatient teaching facility in upstate New York. Prior to the implementation of the smoke-free medical campus policy, it was common to see employees, visitors, and patients lined up outdoors around the main hospital entrances and smoking just beyond the "no smoking" signage. Inpatients could look out their windows at the main entrance or into the courtyard and see hospital staff, other patients, and visitors smoking.

This study prospectively evaluates the impact of implementing the smoke-free medical campus policy and starting an inpatient smoking cessation service. It addresses the following questions that have also been raised by the Task Force for Community Preventive Services. ${ }^{8}$ Does the institution of hospital smoking bans reduce the percentage of inpatients who smoke or increase the percentage who sign out against medical advice? What are the extended effects (beyond 1 year after implementation) of medical campus smoking bans on employee smoking rates?

\section{Materials and Methods}

Policy Implementation

As prior studies have shown that institution of a smoke-free medical campus policy involves much more than just posting 
signage, ${ }^{9,10}$ a detailed multidisciplinary work plan was implemented starting 1.5 years prior to the date our policy went into effect on July 1, 2006. The "Implementing a Smoke-Free Environment" plan, produced by the University of Michigan, ${ }^{11}$ which includes a 15 -step checklist, was used to guide this policy change. ${ }^{12}$ As part of that plan, employees were offered on-site smoking cessation services, including nicotine replacement therapy (NRT), and 150 employees participated in this program prior to July 1, 2006. Staff, community, and patient education was also completed. A new campus map delineating the smoke-free border was disseminated. Signage was posted in areas used in the past for smoking. In addition to implementing this plan, an inpatient smoking cessation service was started 3 months prior to July 1, 2006. In addition to supporting the enforcement of the smoke-free medical campus, our inpatient smoking cessation program was designed to help inpatients with nicotine withdrawal as well as smoking cessation, if they were ready to quit.

\section{Data Collection and Analysis}

The inpatient electronic medical record (EMR) was used to monitor the smoking status of patients admitted to hospital on a monthly basis. On admission to the hospital, the admitting nurse screened patients for current smoking status. This information was entered into the EMR starting in April 2006; therefore, pre-ban screening data were limited to 2 months prior to the ban. Inpatients too sick to complete this screening process, women admitted for labor and delivery, and inpatients boarded in the emergency department were not screened. No identifiers were used in compiling these monthly data.

Nursing reports of inpatients signing out against medical advice (AMA) were compiled in order to compare incidence of AMA pre-ban to post-ban. AMA documentation in our hospital takes the form of a structured incident report that is reliably documented by nursing staff and signed by the attending physician of service.

Computerized inpatient doctors' orders to pharmacy for NRT, dispensed as gum or patch, were monitored 2 years preinitiation and postinitiation of the inpatient smoking cessation service on April 1, 2006. As varenicline was nonformulary and bupropion was used for other indications than smoking cessation, these medications were not included in this review. The Chow test was used to measure and test for significant breaks in a time series analysis of the NRT orders.

New York State law requires an annual occupational health review to be completed by every hospital employee. At our hospital, this review included a question on tobacco use "Do you smoke or chew tobacco?" Although there has been a smoker/nonsmoker differential in the rates offered for supplemental life insurance since 1992, there were no "wellness credits" or other incentives for medical insurance offered in employee benefits that may predispose employees to underreport tobacco use. Using this question, employees were categorized as self-reported current smokers or chew users. Employee smoking rates were estimated using differ- ent denominators to validate the direction of the trend. First, self-reported smoking rates were compared pre-ban and post-ban among a stable cohort of hospital employees ( $\mathrm{n}=489$ ), defined as hospital-based employees with anniversary dates from March to June who reported in both 2005 and 2007. The McNemar test was used to test the statistical significance of the 2 smoking rates of paired replicates in this stable cohort of employees reporting pre-ban and post-ban. Second, all employees in the database reporting smoking status pre-ban, March to June 2005, and then post-ban, March to June 2006 and 2007, were compared in order to monitor trends in employee smoking overall. A ttest was used to compare the statistical significance of the difference in the overall rates of smoking among all employees pre-ban and post-ban.

Internal review boards of our hospital and the New York State Department of Health reviewed and approved this study.

\section{Results}

\section{Inpatient Outcomes}

An average of 959 patients were admitted per month in the 18-month period pre-ban (January 2005 to June 2006) vs. 988 per month in the 23-month period post-ban (July 2006 to September 2008). A monthly average of $89 \%$ of inpatients were screened for tobacco use when admitted. The monthly average for the percentage of inpatients who currently smoke has been approximately $21.6 \%$ following the implementation of the smoke-free hospital plan. There has been little variation (Figure 1) in the percentage of inpatients who smoke pre-ban and post-ban except for the startup period in 2006 and the onset of the 2007 respiratory illness season.

Among all inpatients who currently smoke, $69.8 \%$ received a brief nursing intervention at the time of admission and $25 \%$ received an inpatient visit from our part-time smoking cessation specialist.

The percentage of inpatients who signed out against medical advice (AMA) with the reason of having to smoke was $13.8 \%(4 / 29) 6$ months pre-ban, and $13.6 \%(3 / 22)$ 6 months post-ban. In 2007, there were no inpatients who signed out AMA stating that they needed to smoke. Because the reason for signing out AMA may be underreported, we also examined the rate of smoking among all inpatients who sign out AMA. Six months pre-ban, this percentage was $48.3 \%$ (14/29), but increased 6 months post-ban to $59 \%$ (13/ 22). In 2007, the percentage of smokers among inpatients who sign out AMA leveled off at 50.8\% (29/57).

Review of computerized inpatient prescription orders shows that orders for NRT nearly tripled after the inpatient smoking cessation service started April 1, 2006 (3 months prior to the ban) (Figure 2). Inpatient orders for these medications increased from 832 in a 2-year period before the ban (April 1, 2004 to March 31, 2006) to 2475 in the 2 years following the initiation of the inpatient smoking service (April 1, 2006 to March 31, 2008). The Chow test is highly 


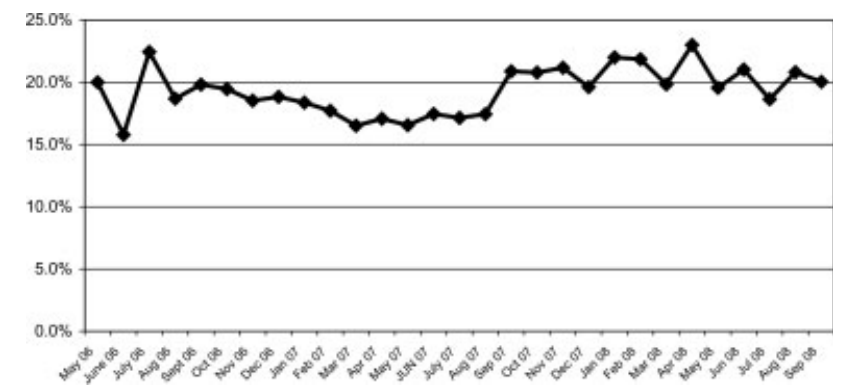

FIGURE 1. Proportion of inpatients who on admission report they currently smoke (smoke-free medical campus began July 1, 2006).

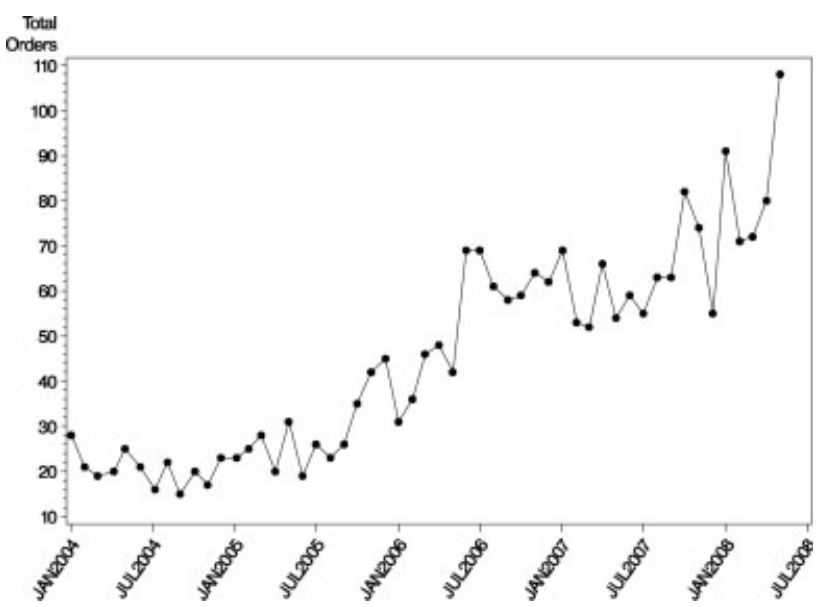

FIGURE 2. Trend in inpatient orders for nicotine replacement therapy (inpatient smoking cessation service began April 1, 2006).

significant for a break point in June $2006(P=0.008)$, 1 month prior to the ban.

\section{Employee Smoking Rates}

Among a cohort of 489 hospital-based employees reporting in both 2005 and 2007, 12\% reported smoking in 2005 and $7.5 \%$ in 2007 (McNemar was significant at $P<0.001$ ). Two employees reported using chewing tobacco in 2005 and only 1 in 2007.

Including all hospital employees reporting any 1 year during their anniversary dates, the self-reported smoking rates were $14.3 \%(\mathrm{n}=624)$ in March to June 2005, $14.8 \%$ ( $\mathrm{n}=661)$ in March to June 2006, and 9.4\% ( $\mathrm{n}=1,112)$ in March to June $2007(P<0.0002)$. Because promotions change the anniversary date, and the database was expanded in 2007 to include new hires and managerial staff, these estimates represent the point prevalence among employees whose anniversary dates fall between March and June.

\section{Discussion}

Following implementation of a smoke-free medical campus, no adverse effects were observed on inpatient volume at our hospital. The percentage of inpatients who smoke and the percentage of inpatients signing out AMA have remained stable after the smoke-free policy went into effect. In addition, selfreported employee smoking rates decreased significantly. Fears about losing inpatients (who smoke) following the implementation of a smoke-free hospital plan were unfounded.

This study employs the electronic medical record to not only monitor trends in the proportion of inpatients who smoke pre-ban and post-ban, but also to notify our inpatient smoking cessation specialist, on the day of admission, to consult on patients who currently smoke. Unfortunately, our cessation specialist, who is part-time, was unable to see all inpatients who smoke on account of the inpatient's acuity, pain, hospice status, weekend or night admission, or not being available due to testing, surgery, or other procedures. Nevertheless, use of NRT increased sharply following the initiation of this program. As shown in Figure 2, a linear rise in NRT orders was already underway starting April 2005, probably in anticipation of the ban and coinciding with the start of the inpatient smoking cessation program. However, the Chow test is highly significant for a breakpoint in June 2006 ( $P=0.008), 1$ month prior to the ban, meaning that the slope was climbing even more steeply after that point.

As hospitalized smokers may be more motivated to stop smoking, the updated 2008 clinical practice guidelines for Treating Tobacco Use and Dependence now recommend that all patients in the hospital be given medications, advised, counseled, and receive follow-up after discharge. ${ }^{13}$ Although our inpatient cessation program was started before these clinical practice guidelines were available, we are currently evaluating the efficacy of our inpatient program by assessing self-reported quit rates 6-months posthospitalization (data collection in process). Provision of inpatient smoking cessation has been shown to be an effective smoking cessation intervention if combined with outpatient follow-up. ${ }^{14}$ Our current program will be expanded to include outpatient follow-up, if the inpatient's primary care provider is unable to provide it or if the inpatient refuses faxed referral to the New York State quit line program.

This study evaluates the impact of simultaneously introduced interventions such as medical campus smoking ban, inpatient smoking cessation program, hospital staff education, and other elements of the University of Michigan Smoke-Free Hospital Implementation Plan. The role of individual components of the plan cannot be evaluated in this study as they were intentionally implemented simultaneously in order to achieve a synergistic effect.

Another limitation of this study is that smoking status is self-reported and not validated biochemically. Although validated smoking status measures such as salivary cotinine testing would be more scientifically valid, it was not feasible to validate the smoking status of inpatients, nor that of employees. Thus smoking status, as ascertained in this study, is 
subject to underreporting. Social desirability bias has been recognized as potential limitation of self-reported smoking status in other evaluations of smoke-free policies. ${ }^{3,4,15}$

In the 1990s, the employee benefits of instituting indoor smoking bans in hospitals were theorized to include reduced employee sick time, break time, and tobacco use, as well as increased motivation for smoking cessation and reduced legitimacy of tobacco use. ${ }^{16,17}$ Peer pressure, workplace socialization, and being forced to stay away from cigarettes for the length of entire workdays have been credited with helping hospital workers to quit. ${ }^{4,7}$ In our study, extending the ban to the outdoor areas of our medical campus as well as provision of employee smoking cessation services may augment these mechanisms. This study extends findings of older studies that showed hospital smoking bans (primarily indoor) decreased hospital employee smoking rates. Currently, our reduced employee smoking rate approaches the Healthy People 2010 goal of $12 \%{ }^{18}$

In conclusion, implementing a smoke-free medical campus does not adversely affect inpatient volume (even among smokers), does not increase inpatient signing out AMA and can significantly increase inpatient NRT use, which in turn can increase the success of a quit attempt. ${ }^{19}$ In addition, implementing an outdoor smoking ban further reduces hospital employee smoking rates.

\section{Acknowledgements}

The authors are grateful to the many Mary Imogene Bassett Hospital staff in administration, employee health, facilities management, human resources, inpatient pharmacy, medical education, patient care service, respiratory care, and security who provided policy support and/or data needed to evaluate policy implementation.

\section{Address for correspondence and reprint requests:}

Anne M. Gadomski, MD, MPH, Research Institute, Bassett Healthcare, One Atwell Road, Cooperstown, NY 13326; Telephone: 607-547-3066; Fax: 607-547-6914; E-mail: anne.gadomski@ bassett.org Received 21 July 2008; revision received 1 December 2008; accepted 7 December 2008.

\section{References}

1. Institute of Medicine. Ending the Tobacco Problem: A Blueprint for the Nation. Washington, DC: National Academies Press; 2007.
2. Naseehmullan S, Lisher L. Smoke-Free Hospital Campus Policies. Washington, DC, Advisory Board Original Inquiry Brief. 2/1/2005. Available at: http://www.roswellpark.org/files/1_2_1/prevention/3\%20-\%20-Advisory\% 20Board\%20smoke\%20free\%20policies.pdf. Accessed March 2009.

3. Offord KP, Hurt RD, Berge KG, Frusti DK, Schmidt L. Effects of the implementation of a smoke-free policy in a medical center. Chest. 1992;102: 1531-1536.

4. Longo DR, Brownson RC, Johnson JC, et al. Hospital smoking bans and employee smoking behavior: results of a national survey. JAMA. 1996; 275(16):1252-1257.

5. Wheeler JG, Pulley L, Felix HC, et al. Impact of a smoke-free hospital campus policy on employee and consumer behavior. Public Health Rep. 2007;122(6):744-752.

6. Lin D, Stahl DC, Ikle D, Grannis FW. Employee attitudes and smoking behavior at the City of Hope National Medical Center smoke-free campus. J Natl Compr Canc Netw. 2006;4(6):535-542.

7. Stave GM, Jackson GW. Effect of a total work-site ban on employee smoking and attitudes. J Occup Med. 1991;33(8):884-890.

8. Hopkins DP, Briss PA, Ricard CJ, et al. Reviews of evidence regarding interventions to reduce tobacco use and exposure to environmental tobacco smoke. Am J Prev Med. 2001;20(2S):16-66.

9. Nagle AL, Schofield MJ, Redman S. Smoking on hospital grounds and the impact of outdoor smoke-free zones. Tob Control. 1996;5:199-204.

10. Passannannte MR, Espenshade J, Reichman LB, Hymowitz N, Sia A. The making of a smoke free hospital may not be as easy as you think. Am J Prev Med. 1991;7(4):214-218.

11. University of Michigan Health System. Tobacco Consultation Service. Available at: http://www.med.umich.edu/mfit/tobacco/freeenvironment. htm. Accessed March 2009.

12. Michigan Health and Hospital Association. It's a matter of life and health: MHA campaign for smoke-free hospitals. Available at: http://www. mhasmokefreecampus.org. Accessed March 2009.

13. Department of Health and Human Services (DHHS). Treating Tobacco Use and Dependence: 2008 Update. Chapter 7: Specific Populations and Other Topics. Available at: http://www.ncbi.nlm.nih.gov/books/bv.fcgi? rid=hstat2.section.28504. Accessed March 2009.

14. Rigotti NA, Munafo MR, Stead LF. Interventions for smoking cessation in hospitalized patients. Cochrane Database Syst Rev. 2007;(3):CD001837.

15. Stillman FA, Becker DM, Swank RT, et al. Ending smoking at the Johns Hopkins Medical Institutions: an evaluation of smoking prevalence and indoor air pollution. JAMA. 1990;264:1565-1569.

16. Hurt RD. Toward smoke-free medical facilities. Chest. 1990;97:1027-1028.

17. Fairbanks LL. The benefits of smoke-free health care campuses. Am Fam Physician. 1994;49(1):28-33.

18. U.S. Department of Health and Human Services. Healthy People 2010. Vol 1 2nd ed. Washington, DC: U.S. Department of Health and Human Services; 2000.

19. Wu P, Kumanan W, Dimoulas P, Mills EJ. Effectiveness of smoking cessation therapies: a systematic review and meta-analysis. BMC Public Health. 2006;6:300. 